\title{
Non Complete Response/Non Progressive Disease
}

National Cancer Institute

\section{Source}

National Cancer Institute. Non Complete Response/Non Progressive Disease. NCI

Thesaurus. Code C96700.

Persistence of one or more non-target lesion(s) and/or maintenance of tumor marker levels above the normal limits. (RECIST) 